\title{
BIWEEKLY ADMINISTRATION OF IRINOTECAN (CPT-11) PLUS CISPLATIN WITH AN ANTIDIARRHEAL PROGRAM OF INTESTINAL ALKALIZATION TO REDUCE DIARRHEA IN CANCER PATIENTS
}

\author{
Kunihiko Kobayashi, 2), Toshikazu Sakuyamaa, 3), Wasaburo Koizumi ${ }^{1,4)}$, Atsushi Sato ${ }^{1), 5)}$, \\ Hideki Konishi ${ }^{1,6)}$, Atsushi Shimizu ${ }^{1,7)}$, Mototsugu Fujimori ${ }^{1), 8}$, Rintaro Noro ${ }^{1), 9)}$, \\ Futoshi Kotajima $^{2), 3)}$, Shoji Kudoh ${ }^{1)}$, Minoru Kurihara ${ }^{1)}$ \\ ${ }^{1)}$ Tokyo Cooperative Oncology Group (TCOG), ${ }^{2)}$ Saitama International Medical Center, ${ }^{3)}$ Jikei University School of Medicine, \\ ${ }^{4)}$ Kitazato University East Hospital, ${ }^{5)}$ Showa University Hospital, ${ }^{6}$ Nippon Medical School Second Hospital, \\ ${ }^{77}$ Japan Medical Alliance Ebina General Hospital, ${ }^{8}$ Kimitsu Chuo Hospital, ${ }^{9}$ Nippon Medical School
}

\begin{abstract}
Background: Previously, we reported that the maximum tolerated dose (MTD) of biweekly administration of irinotecan (CPT-11) plus cisplatin (CDDP) was $70 \mathrm{mg} / \mathrm{m}^{2}$ plus $30 \mathrm{mg} / \mathrm{m}^{2}$, respectively. The same biweekly regimen was combined with intestinal alkalization to address delayed diarrhea in this phase I study.

Methods: CPT-11 plus CDDP were administered biweekly with an antidiarrheal program consisting of sodium bicarbonate and magnesium oxide to patients with various malignancies. CDDP dosing was fixed at $30 \mathrm{mg} / \mathrm{m}^{2}$ and dose escalation of CPT-11 from $60 \mathrm{mg} / \mathrm{m}^{2}$ to $100 \mathrm{mg} / \mathrm{m}^{2}$ by a step of $10 \mathrm{mg} / \mathrm{m}^{2}$ was used.

Results: A total of 22 patients (Level I $\left(60 \mathrm{mg} / \mathrm{m}^{2}\right): 3$ patients, Level II $\left(70 \mathrm{mg} / \mathrm{m}^{2}\right): 3$ patients, Level III $\left(80 \mathrm{mg} / \mathrm{m}^{2}\right): 7$ patients, Level IV $\left(90 \mathrm{mg} / \mathrm{m}^{2}\right): 6$ patients, and Level V $\left(100 \mathrm{mg} / \mathrm{m}^{2}\right): 3$ patients) entered into this study. Of the 22 patients, diarrhea of grade 2 and 3 was observed in 3 patients and 1 patient (5\%), respectively. At Level IV, 2 patients experienced grade 3 neutropenia, and one of the 2 patients coincidentally had grade 3 thrombocytopenia and grade 3 diarrhea. At Level V, there were no patients with dose limiting toxicities, but 2 of the 3 patients could not be dosed more than three times. Of the 22 patients, 19 patients were assessed for response. One and 12 patient had partial response and stable disease, respectively, resulting in a disease control rate of $68 \%$.

Conclusion: Intestinal alkalization could prevent CPT-11-induced diarrhea and increase MTD of biweekly $100 \mathrm{mg} / \mathrm{m}^{2}$ of CPT-11 with CDDP $30 \mathrm{mg} / \mathrm{m}^{2}$ administration.
\end{abstract}

Key Words: phase I, CPT-11, diarrhea, transport, biochemical modulation

(Received June 14, 2012; Accepted August 31, 2012)

\section{Introduction}

A combination chemotherapy of CPT-11 and cisplatin (CDDP) showed a synergistic effect in vitro ${ }^{1)}$. And it is used for patients with many malignancies ${ }^{2-4)}$. For example, untreated patients with extensive small cell lung cancer (SCLC) showed an improvement in overall survival when treated with CPT-11 and CDDP compared with patients treated with CDDP/etoposide in a randomized phase III study ${ }^{2}$. In a phase II study for gastric cancer, when CDDP $80 \mathrm{mg} / \mathrm{m}^{2}$ on day 1 was combined with CPT-11 $70 \mathrm{mg} / \mathrm{m}^{2}$ on days 1 and 15 in 4 weeks, the response rate was $48 \%{ }^{4)}$. However, this two-drug com-

Correspondence: Kunihiko Kobayashi MD, PhD, Department of Respiratory Medicine, Saitama International Medical Center, Saitama Medical University, 13971 Yamane, Hidaka City, Saitama, 350-1298, Japan. TEL and Fax 81-42-984-4667, e-mail: kobakuni@saitama-med.ac.jp bination had a high frequency of grade 3 and 4 diarrhea and neutropenia ${ }^{2-4)}$, resulting in lower dose delivered than planned dose. Both delayed diarrhea, which typically presented 5 days after and beyond the initial CPT-11 administration, and neutropenia are recognized as doselimiting toxicities (DLT) of CPT-11 plus CDDP.

A maximal synergistic effect on tumor cells has been observed by the simultaneous combination of CDDP and CPT-11 in vitro ${ }^{1)}$. We confirmed that the cytotoxicity of CDDP is dependent on the area under the concentrationtime curve (AUC) $)^{5}$, indicating that if the AUC per month was maintained, the anti-tumor activity of CDDP was not weakened by the divided administration of the maximal dose. Phase I studies for the weekly administration of CPT-11 concurrently with divided CDDP was reported by us ${ }^{5)}$ and Salts B et al. ${ }^{6}$. On the other hand, in 2005, we reported a phase I study investigating the biweekly administration of CPT-11 plus CDDP, using patients 
with gastrointestinal cancers ${ }^{8,9)}$. The dose of CPT-11 was increased while fixing the dose of CDDP at $30 \mathrm{mg} / \mathrm{m}^{2}$, and the maximum tolerated dose (MTD) of CPT-11 was found to be $70 \mathrm{mg} / \mathrm{m}^{2}$. The dose limiting toxicities were identified to be both leucopenia and delayed diarrhea.

To overcome these side-effects, the metabolic pathway of CPT-11 in the liver has been investigated. CPT11 is metabolized to an active form, 7-ethyl-10-hydroxycamptothecin (SN-38), by carboxyl esterase ${ }^{10)}$, and SN-38 is deactivated to SN-38 glucuronide (SN38-Glu) by UDPglucuronosyltransferase (UGT) in the liver ${ }^{11}$. The UGT gene has a polymorphism of its gene, and gene analysis of UGT-1A1 can predict leucopenia ${ }^{12)}$. However, the prediction delayed diarrhea by UGT-1A1 polymorphism has shown difficulties. Thus, delayed diarrhea remains problematic in clinical practice ${ }^{13)}$.

We have designed an anti-diarrheal program for CPT11 designated as oral alkalization (OA) and control of defecation $(\mathrm{CD})^{14)}$, which is now widely termed intestinal alkalization. To develop a practical and well tolerated regimen using the biweekly administration of CPT-11 plus CDDP, this two drug regimen was combined with intestinal alkalization. This phase I study investigated whether the MTD of CPT-11 plus CDDP observed in our previous study mentioned above may be increased by intestinal alkalization.

\section{Patients and Methods}

The protocol employed in this study followed that of our previous study ${ }^{9)}$ except for adding the intestinal alkalization. This study was performed in accordance with the Helsinki Declaration (amended in 2003) of the World Medical Association, and the protocol was approved by the institutional review board of each participating institution.

\section{Patients entered}

Prior to their participation in the study, patients admitted to 8 institutions were examined to ensure that they met the following criteria: (a) histologic or cytologic diagnosis of lung cancer, gastrointestinal cancer, gynecological cancer or breast cancer, with an indication for CPT-11 treatment in Japan, (b) more than 4 weeks after the previous therapy or no previous chemotherapy, (c) performance status (PS) of 2 or better on the Eastem Cooperative Oncology Group scale, (d) age from 20 to 75 years old, (e) adequate bone marrow function (white blood cell (WBC) count $>=4,000 / \mathrm{mm}^{3}$, plt $>=100,000 /$ $\mathrm{mm}^{3}, \mathrm{Hb}>=9.0 \mathrm{~g} / \mathrm{dl}$ ), (i) adequate hepatic function (T-Bil<=1.5 mg/dl, aminotransferases less than twice the upper limit of normal), (g) adequate renal function (S-Cr $<=1.5 \mathrm{mg} / \mathrm{d} 1$ ), (h) no diarrhea and no ileus, (i) no interstitial pneumonitis, and (i) no medical problems severe enough to prevent compliance with the study requirements. All patients provided informed consent before enrollment in the study according to institutional guidelines.

\section{Treatment schedule (Fig. 1)}

Based on the MTD of our previous phase I study of biweekly CPT-11 plus CDDP without the intestinal alkalization $^{9)}$, the starting doses of CPT-11 and CDDP were set at $60 \mathrm{mg} / \mathrm{m}^{2}$ and $30 \mathrm{mg} / \mathrm{m}^{2}$, respectively, on days 1 and 15 in 4 weeks. CDDP dosing was fixed at $30 \mathrm{mg} / \mathrm{m}^{2}$, and dose escalation of CPT-11 was performed from 60 $\mathrm{mg} / \mathrm{m}^{2}$ to $100 \mathrm{mg} / \mathrm{m}^{2}$ in steps of $10 \mathrm{mg} / \mathrm{m}^{2}$ (Level I : 60 $\mathrm{mg} / \mathrm{m}^{2}$, Level II: $70 \mathrm{mg} / \mathrm{m}^{2}$, Level III: $80 \mathrm{mg} / \mathrm{m}^{2}$, Level IV: $90 \mathrm{mg} / \mathrm{m}^{2}$, and Level V: $100 \mathrm{mg} / \mathrm{m}^{2}$ ).

Initially, CPT-11 was administered in $500 \mathrm{ml}$ normal saline as a 90-min i.v. infusion. Then CDDP was given during a 60-min period. Patients with no evidence of disease progression were treated at least 2 cycles. In the present study, the intestinal alkalization was employed to prevent late diarrhea ${ }^{14)}$. Coinciding with day one of CPT11 infusion and for four days thereafter, the following was administered: sodium bicarbonate powder, $2.0 \mathrm{~g} /$ day t.i.d. (between meals) and magnesium oxide powder, $1.5 \mathrm{~g} /$ day, t.i.d. (after meals). The dose of magnesium oxide was increased or decreased with the occurrence of constipation or diarrhea, respectively. For prevention of emesis, 5-hydroxytryptamine 3 receptor antagonist and dexamethasone were given i.v. prior to the administration of CPT-11 and CDDP. To avoid CDDP-induced renal damage, d.i.v. hydration with a total of $1,500 \mathrm{ml}$ was performed.

Granulocyte colony-stimulating factor (G-CSF) was administered when grade 4 leukopenia $(<1,000 /$ $\left.\mathrm{mm}^{3}\right)$ and/or neutropenia $\left(<500 / \mathrm{mm}^{3}\right)$ were observed. Erythropoietin was not used. Delayed diarrhea was treated with a high dose of loperamide according to previous reports ${ }^{11)}$. Persistent or grade 3 or greater diarrhea, despite loperamide therapy, warranted the use of intravenous hyperalimentation for fluid management.

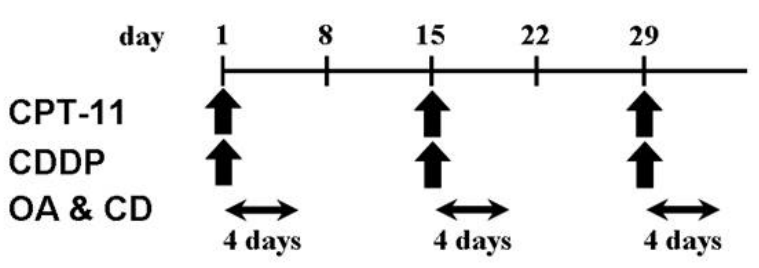

Fig. 1. Treatment Schedule CPT-11 plus CDDP were administered biweekly with an antidiarrheal program, $\mathrm{OA}$ and $\mathrm{CD}$, consisting of sodium bicarbonate and magnesium oxide. CDDP dosing was fixed at $30 \mathrm{mg} / \mathrm{m}^{2}$ and dose escalation of CPT-11 from $60 \mathrm{mg} / \mathrm{m}^{2}$ to $100 \mathrm{mg} / \mathrm{m}^{2}$ by increments of $10 \mathrm{mg} / \mathrm{m}^{2}$ was performed. (Level I: $60 \mathrm{mg} / \mathrm{m}^{2}$, Level II: $70 \mathrm{mg} / \mathrm{m}^{2}$, Level III: $80 \mathrm{mg} / \mathrm{m}^{2}$, Level IV: 90 $\mathrm{mg} / \mathrm{m}^{2}$, and Level V: $100 \mathrm{mg} / \mathrm{m}^{2}$ ) 


\section{Evaluation}

Patients underwent staging evaluation before entry of this study, and the staging procedures followed those of the tumor-node-metastasis (TNM) system. Tumor response was classified in accordance with World Health Organization criteria. Also, before the first course, a complete blood cell count (CBC), serum chemistry for renal and hepatic function, electrolyte analysis, and urinalysis were performed. These studies were repeated at least once a week after the initial evaluation. The NCI Common Toxicity Criteria was used to grade organ system damage.

Dose limiting toxicities (DLT) were defined as Grade 4 hematologic toxicity or Grade 3 non-hematologic toxicity except for emesis and alopecia. During the course of treatment, the dose of CPT-11 and CDDP was withheld when leukopenia $\left(<3,000 / \mathrm{mm}^{3}\right)$ and/or diarrhea in excess of grade 1 was present on the day of planned administration. Administration delay over 1 week was also judged as DLT. Maximum tolerated dose (MTD) was defined at the dose which produces more than $50 \%$ patients with DLT. Namely, if the first 3 patients experienced no DLT, dose escalation was made; if the first 3 patients experienced DLT, the dose was MTD; if 1 or 2 patients experienced DLT, additional 3 patients were treated by the same dose. If 1 or 2 patients of the total 6 patients experienced DLT, dose escalation was made, but if $>=3$ patients of the total 6 patients experienced DLT, the dose was judge to be MTD.

\section{Results}

Twenty three patients participated in the trial. One patient dropped out of the study because of the patient's refusal prior to treatment. The characteristics of the 22 patients are shown in Table 1. Three patients were women and 19 were men, and the median age was 61 years. Most of the patients had a good PS, but 2 patients were PS 2 . Primary sites of malignancy were the lung: 11 patients, the stomach: 2 patients, the large intestine: 6 patients, and the uterine and ovary: 2 patients.

Twenty two patients were assessable for toxicity. Table 2 and 3 shows hematologic toxicity and nonhematologic toxicity, respectively. The leukocyte count nadir usually occurred around day 21 . However, grade 4 leukopenia and neutropenia occurred in none of the patients. Thrombocytopenia occurred less frequently than leukopenia and was less severe. Thrombocytopenia of grade 3 or more was observed in level IV. No patient required platelet transfusion. Grade $>=2$ diarrhea was observed in 4 patients (18\%) of the 22 patients, but grade 3 diarrhea occurred only in 1 patient (5\%), who required i.v. hydration and recovered within seven days. Four patients experienced grade 3 nausea or vomiting (18\%), indicating that nausea and vomiting were modest with
Table 1. Patient characteristics

\begin{tabular}{lc}
\hline Male/female & $19 / 3 \mathrm{pts}$ \\
Median age & 61 \\
(Range) & $(38-72)$ \\
Performance status & \\
0 & $10 \mathrm{pts}$ \\
1 & $10 \mathrm{pts}$ \\
2 & $2 \mathrm{pts}$ \\
Cancer type & \\
NSCLC & $9 \mathrm{pts}$ \\
SCLC \#\# & $2 \mathrm{pts}$ \\
Gastric cancer & $3 \mathrm{pts}$ \\
Colonic cancer & $6 \mathrm{pts}$ \\
Gynecological cancer & $2 \mathrm{pts}$ \\
Previous therapy & \\
No & $4 \mathrm{pts}$ \\
Yes & $18 \mathrm{pts}$ \\
Chemotherapy & $18 \mathrm{pts}$ \\
Radiation therapy & $7 \mathrm{pts}$ \\
Operation & $9 \mathrm{pts}$ \\
Others & $1 \mathrm{pt}$ \\
\hline
\end{tabular}

\# NSCLC: non-small cell lung cancer

\#\#CLC : small cell lung cancer

this regimen. No hepatic, renal and pulmonary toxicities related to drug administration were observed in this trial. No treatment-related death was observed.

From the view point of dose escalation of CPT-11, at Levels I and II (CPT-11 60, $70 \mathrm{mg} / \mathrm{m}^{2}$ and CDDP 30 $\mathrm{mg} / \mathrm{m}^{2}$ ), no DLT was observed. At level III (CPT-11 80 $\mathrm{mg} / \mathrm{m}^{2}$ and CDDP $30 \mathrm{mg} / \mathrm{m}^{2}$ ), one patient ceased the second administration because of disease progression, and, therefore, the total number of level III patients was 7. Administration delay over 3 weeks occurred in one patient of the other 6 patients. At level IV (CPT-11 90 $\mathrm{mg} / \mathrm{m}^{2}$ and CDDP $30 \mathrm{mg} / \mathrm{m}^{2}$ ), 2 patients experienced grade 3 neutropenia, and one of the 2 patients had grade 3 thrombocytopenia and grade 3 diarrhea. Furthermore, 2 patients experienced grade 3 emesis. Only one of the 6 patients entered at level IV had DLT, and, therefore, dose escalation was made. At level V (CPT-11 $100 \mathrm{mg} / \mathrm{m}^{2}$ and CDDP $30 \mathrm{mg} / \mathrm{m}^{2}$ ), one of the 3 patients experienced grade 3 emesis, indicating that level $\mathrm{V}$ was not judged to be MTD according to the study protocol. However, further dose escalation was not made. Two of the 3 patients could not be given more than three biweekly CPT-11 100 $\mathrm{mg} / \mathrm{m}^{2}$ and CDDP $30 \mathrm{mg} / \mathrm{m}^{2}$ due to emesis. Therefore, biweekly CPT-11 $90 \mathrm{mg} / \mathrm{m}^{2}$ with CDDP $30 \mathrm{mg} / \mathrm{m}^{2}$ with intestinal alkalization was recommended in clinical practice.

The median administration frequency of CPT-11 and CDDP was 4 times with a range from 1 to 16 times. Four patients had no previous treatment, and the other 18 patients had previous chemotherapy. Of the 22 patients, 19 patients were assessed for response (Table 4). One patient and 12 patient had partial response (PR) and stable disease (SD), respectively, resulting in a disease control rate of $68 \%$. 
Table 2. Hematologic toxicities $(n=22)$

\begin{tabular}{|c|c|c|c|c|c|c|c|c|c|c|c|c|c|c|c|c|c|}
\hline \multirow[t]{2}{*}{ Level $^{\#}$} & \multirow[t]{2}{*}{$\mathbf{n}$} & \multicolumn{4}{|c|}{$\begin{array}{l}\text { Leucopenia } \\
\text { CTC Grade }^{\# \#}\end{array}$} & \multicolumn{4}{|c|}{$\begin{array}{l}\text { Neutropenia } \\
\text { CTC Grade }^{\# \#}\end{array}$} & \multicolumn{4}{|c|}{$\begin{array}{c}\text { Anemia } \\
\text { CTC Grade }^{\# \#}\end{array}$} & \multicolumn{4}{|c|}{$\begin{array}{l}\text { Platelet depletion } \\
\text { CTC Grade }^{\# \#}\end{array}$} \\
\hline & & 1 & 2 & 3 & 4 & 1 & 2 & 3 & 4 & 1 & 2 & 3 & 4 & 1 & 2 & 3 & 4 \\
\hline I & 3 & 1 & 1 & 0 & 0 & 2 & 0 & 0 & 0 & 1 & 1 & 0 & 0 & 0 & 0 & 0 & 0 \\
\hline II & 3 & 1 & 1 & 1 & 0 & 0 & 1 & 0 & 0 & 1 & 0 & 0 & 0 & 0 & 0 & 0 & 0 \\
\hline III & 7 & 4 & 1 & 0 & 0 & 1 & 0 & 0 & 0 & 0 & 2 & 0 & 0 & 0 & 1 & 0 & 0 \\
\hline IV & 6 & 1 & 1 & 1 & 0 & 1 & 0 & 2 & 0 & 1 & 0 & 2 & 0 & 0 & 0 & 1 & 0 \\
\hline $\mathbf{V}$ & 3 & 0 & 1 & 0 & 0 & 0 & 0 & 0 & 0 & 1 & 1 & 0 & 0 & 0 & 0 & 0 & 0 \\
\hline
\end{tabular}

\# CDDP $30 \mathrm{mg} / \mathrm{m}^{2}$ plus CPT-11 at a dose of Level I: $60 \mathrm{mg} / \mathrm{m}^{2}$, Level II: $70 \mathrm{mg} / \mathrm{m}^{2}$, Level III: $80 \mathrm{mg} / \mathrm{m}^{2}$, Level IV: $90 \mathrm{mg} / \mathrm{m}^{2}$, or Level V: $100 \mathrm{mg} / \mathrm{m}^{2}$

\# CTC Grade: the NCl Common Toxicity Criteria (version 2.0)

Table 3. Non-hematologic toxicities $(n=22)$

\begin{tabular}{|c|c|c|c|c|c|c|c|c|c|c|c|c|c|c|c|c|c|}
\hline \multirow[t]{2}{*}{ Level $^{\#}$} & \multirow[t]{2}{*}{$\mathbf{n}$} & \multicolumn{4}{|c|}{$\begin{array}{c}\text { Diarrhea } \\
\text { CTC Grade }^{\# \#}\end{array}$} & \multicolumn{4}{|c|}{$\begin{array}{c}\text { Emesis } \\
\text { CTC Grade }^{\# \#}\end{array}$} & \multicolumn{4}{|c|}{$\begin{array}{l}\text { Appetite loss } \\
\text { CTC Grade }\end{array}$} & \multicolumn{4}{|c|}{$\begin{array}{l}\text { Abdominal pain } \\
\text { CTC Grade }^{\# \#}\end{array}$} \\
\hline & & 1 & 2 & 3 & 4 & 1 & 2 & 3 & 4 & 1 & 2 & 3 & 4 & 1 & 2 & 3 & 4 \\
\hline I & 3 & 1 & 0 & 0 & 0 & 0 & 0 & 0 & 0 & 1 & 0 & 0 & 0 & 0 & 0 & 0 & 0 \\
\hline II & 3 & 1 & 0 & 0 & 0 & 0 & 1 & 1 & 0 & 1 & 0 & 1 & 0 & 0 & 0 & 0 & 0 \\
\hline III & 7 & 2 & 2 & 0 & 0 & 2 & 0 & 0 & 0 & 1 & 1 & 0 & 0 & 0 & 0 & 0 & 0 \\
\hline IV & 6 & 1 & 1 & 1 & 0 & 2 & 0 & 2 & 0 & 2 & 0 & 2 & 0 & 0 & 0 & 0 & 0 \\
\hline $\mathbf{V}$ & 3 & 1 & 0 & 0 & 0 & 1 & 2 & 1 & 0 & 0 & 2 & 1 & 0 & 0 & 0 & 0 & 0 \\
\hline
\end{tabular}

\# CDDP $30 \mathrm{mg} / \mathrm{m}^{2}$ plus CPT-11 at a dose of Level I: $60 \mathrm{mg} / \mathrm{m}^{2}$, Level II: $70 \mathrm{mg} / \mathrm{m}^{2}$, Level III: $80 \mathrm{mg} / \mathrm{m}^{2}$, Level IV: $90 \mathrm{mg} / \mathrm{m}^{2}$, or Level V: $100 \mathrm{mg} / \mathrm{m}^{2}$

\# CTC Grade: the NCl Common Toxicity Criteria (version 2.0)

Table 4. Dosing and Response Rate

\begin{tabular}{|c|c|c|c|c|c|c|c|}
\hline Dosing & $\begin{array}{c}\text { Times given } \\
\text { Median } \\
\text { Range }\end{array}$ & & & & & & $\begin{array}{c}4 \\
1-16\end{array}$ \\
\hline & Overall & $\begin{array}{c}\mathrm{CR} \\
0\end{array}$ & $\begin{array}{c}\mathrm{PR} \\
1\end{array}$ & $\begin{array}{l}\text { SD } \\
12\end{array}$ & $\begin{array}{c}\mathrm{PD} \\
6\end{array}$ & $\begin{array}{c}\mathrm{NE} \\
3\end{array}$ & $\begin{array}{c}\text { Disease control rate } \\
13 / 19(68 \%)\end{array}$ \\
\hline
\end{tabular}

\# CR: complete response, PR: partial response, SD: stable disease and PD: progressive disease was classified in accordance with World Health Organization criteria.

\section{Discussion}

The Food and Drug Administration (FDA) recommends to test for UGT-1A1 polymorphisms before the administration of CPT-11. This gene analysis can predict leucopenia, but in terms of prediction of diarrhea ${ }^{13)}$, the FDA recognizes that the assay has difficulty. To explain this, a two-compartment model constructed by the liver and the intestine to metabolizing CPT-11 has been considered (Fig. 2). The liver compartment, as described in the Introduction, has UGT as a key enzyme ${ }^{11,12)}$. In the intestinal compartment ${ }^{15)}$, CPT-11, SN-38 and SN$38 \mathrm{G}$ are secreted into bile by hepatocytes with subsequent excretion into the intestine ${ }^{16,17)}$. It was reported that $\mathrm{SN}-38 \mathrm{G}$ is transformed to active $\mathrm{SN}-38$ by bacterial beta-glucuronidase $^{18)}$. In reports from us and other researchers, damage in the small intestine was observed in humans ${ }^{7,19)}$ where little bacteria exist and, therefore, another key of CPT-induced diarrhea was considered.

We found that the intestinal absorption of CPT-11 and $\mathrm{SN}-38$ was characteristic of that of weakly basic drugs ${ }^{20)}$.
At acid $\mathrm{pH}$ in the intestinal lumen, non-ionic lactone forms of CPT-11 and SN-38 are passively transported, and their uptake rates are very rapid. On the other hand, the respective anionic carboxylate forms are actively and slowly absorbed at basic $\mathrm{pH}$. Non-ionic SN-38 lactone is more cytotoxic than anionic SN-38 carboxylate, and the uptake rate of SN-38 correlated with its cytotoxicity of intestinal epithelium model in vitro ${ }^{20)}$, indicating that elevating $\mathrm{pH}$ in the intestinal lumen might result in a reduced cytotoxic effect on the intestinal epithelium. And, in vivo, hamster's damaged diarrhea was found to be reduced by sodium bicarbonate ${ }^{27)}$.

We have designed an anti-diarrheal program for CPT11 designated as the $\mathrm{OA}$ and $\mathrm{CD}$, which is also called intestinal alkalization. Its rationale was constructed on the intestinal compartment in metabolizing CPT-11 mentioned above (Fig. 2). The rationale in designing intestinal alkalization was to reduce absorption of active SN-38 lactone by intestinal cells, which should in turn reduce epithelial damage and its impact on subsequent delayed diarrhea (US patented). The intestinal alkalization consisted of an oral administration of sodium bicarbonate 


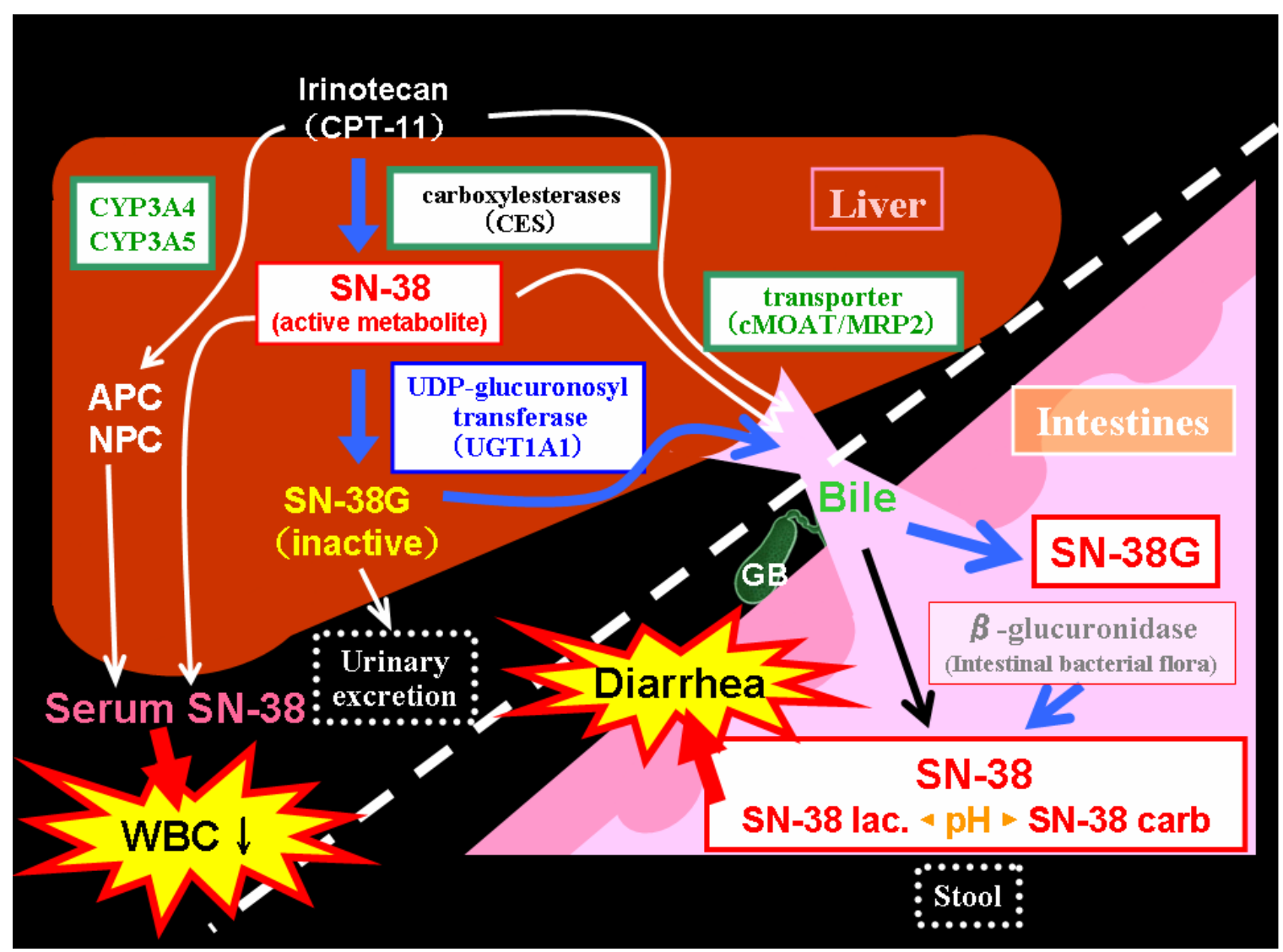

Fig. 2. Metabolic mechanism of CPT-11

A two-compartment model constructed by the liver and the intestine is considered in metabolizing CPT-11. The liver compartment, with UGT as a key enzyme, mainly determines myelosuppression. On the other hand, the intestinal compartment, in which intestinal $\mathrm{pH}$ is critical for the intestinal epithelium to absorb cytotoxic SN-38 lactone, is considered to cause intestinal damage, resulting in diarrhea.

and magnesium oxide ${ }^{14)}$. The two agents have a basic $\mathrm{pH}$. Magnesium oxide demonstrates a laxative action, which should shorten the dwelling time of CPT-11 and SN-38 within the intestine. The intestinal alkalization has succeeded in reducing late diarrhea by CPT-11 in pleural studies $^{14,21-24)}$.

We previously conducted a phase I/II study of biweekly CPT-11 with CDDP without the intestinal alkalization $^{9)}$. Dose-limiting toxicities were diarrhea and neutropenia, and MTD was a CPT-11 dose of $70 \mathrm{mg} /$ $\mathrm{m}^{2}$ with CDDP $30 \mathrm{mg} / \mathrm{m}^{2}$. The recommended dose was set at biweekly CPT-11 $60 \mathrm{mg} / \mathrm{m}^{2}$ with CDDP $30 \mathrm{mg} / \mathrm{m}^{2}$ without the intestinal alkalization. Our present study has the same protocol as the previous study except for adding the intestinal alkalization. The MTD was over level V (biweekly CPT-11 $100 \mathrm{mg} / \mathrm{m}^{2}$ plus CDDP $30 \mathrm{mg} / \mathrm{m}^{2}$ ), indicating that the intestinal alkalization could elevate the dose of CPT-11 by reducing intestinal toxicities. Late diarrhea was not DLT in the present study.

The response rate and disease control rate of the present study were $5 \%$ and $68 \%$, respectively. Whether these values are favorable or not is difficult to determine because of using heavily treated patients with pleural primary sites of malignancy. Considering the reduction of absorption by intestinal epithelium of SN-38 and CPT11 , the intestinal alkalization may influence on enterohepatic circulation and their pharmacokinetics. Hamada et al. reported a case report, in which intestinal alkalization decreased the plasma levels of CPT-11 and SN-38 ${ }^{25}$. However, Tamura $\mathrm{T}$ et al. compared the pharmacokinetics of CPT-11 with and without intestinal alkalization in a cross-over study using 10 colorectal cancer patients ${ }^{26)}$. They found that the blood levels of CPT-11 and SN-38 were statistically equivalent between patients with and without intestinal alkalization. Furthermore, as the result of a case-control study and other phase II studies ${ }^{14,21-23)}$, intestinal alkalization could elevate dose-intensity and total dosing of CPT-11, and, in turn, all the studies described favorable response rates.

In conclusion, intestinal alkalization could prevent CPT-11-induced diarrhea and increase MTD up to biweekly $100 \mathrm{mg} / \mathrm{m}^{2}$ of CPT-11 with CDDP $30 \mathrm{mg} /$ $\mathrm{m}^{2}$. Considering the repeatability of this treatment, the recommended dose was set at biweekly CPT-11 $90 \mathrm{mg} /$ $\mathrm{m}^{2}$ with CDDP $30 \mathrm{mg} / \mathrm{m}^{2}$ with intestinal alkalization in clinical practice. 


\section{References}

1) Matsumoto N, Nakao S, Esaki T, Fujishima H, Tatsumoto T, Niho Y. (1995) Inhibition of cis-diamminedichloroplatinum (II)-induced DNA interstrand cross-link removal by 7-ethyl-10-hydroxy-camptothecin in HST-1 human squamous-carcinoma cells. Int J Cancer 62: 70-75.

2) Noda K, Nishiwaki Y, Kawahara M, Negoro S, Sugiura T, Yokoyama A, Fukuoka M, Mori K, Watanabe K, Tamura T, Yamamoto S, Saijo N. (2002) Irinotecan plus cisplatin compared with etoposide plus cisplatin for extensive small-cell lung cancer. $\mathrm{N}$ Engl J Med 346: 85-91.

3) Ohe Y, Ohashi Y, Kubota K, Tamura T, Nakagawa K, Negoro S, Nishiwaki Y, Saijo N, Ariyoshi Y, Fukuoka M. (2007) Randomized phase III study of cisplatin plus irinotecan versus carboplatin plus paclitaxel, cisplatin plus gemcitabine, and cisplatin plus vinorelbine for advanced non-small-cell lung cancer: Four-Arm Cooperative Study in Japan. Ann Oncol. 18(2):317-23.

4) Boku N, Ohtsu A, Shimada Y, Shirao K, Seki S, Saito H, Sakata Y, Hyodo I. (1999) Phase II study of a combination of irinotecan and cisplatin against metastatic gastric cancer. J Clin Oncol. 17(1):31923.

5) Kobayashi K, Kudoh S, Takemoto T, Hino M, Hayashihara K, Nakahiro K, Ando M, Niitani H. (1995) In vitro investigation of a combination of two drugs, cisplatin and carboplatin, as a function of the area under the c/t curve. J Cancer Res Clin Oncol 121: 715720.

6) Saltz B, Spriggs D, Schaaf J, Schwartz K, Ilson D, Kemeny N, Kanowitz J, Steger C, Eng M, Albanese P, Semple D, Hanover K, Elfring L, Miller L, Kelsen D. (1998) Phase I clinical and pharmacologic study of weekly cisplatin combined with weekly irinotecan in patients with advanced solid tumors. J Clin Oncol 16: 3858 3865.

7) Kobayashi K, Shinbara A, Kamimura M, Takeda Y, Kudo K, Kabe J, Hibino S, Hino M, Shibuya M, Kudoh S. (1998) Irinotecan (CPT11 ) in combination with weekly administration of cisplatin (CDDP) for non-small-cell lung cancer. Cancer Chemother Pharmacol 42: 53-58.

8) Sato A, Kurihara M, Matsukawa M, Shimada K, Yamazaki T, Nakamachi M, Koda T. (2001) Preliminary study of fortnightly CPT-11 hydrochloride plus cisplatin therapy in patients with advanced gastric and colorectal cancer. Cancer Chemother Pharmacol. 47(5):380-4.

9) Koizumi W, Kurihara M, Satoh A, Takiguchi H, Tanabe S, Shimada K, Iwasaki R, Saigenj K. (2005) Phase 1/ll study of biweekly CPT-11 plus cisplatin in the treatment of advanced gastric cancer. Anticancer Res. 25(2B):1257-62.

10) Rivory LP, Bowles MR, Robert J, Pond SM. (1996) Conversion of irinotecan (CPT-11) to its active metabolite, 7-ethyl-10-hydroxycamptothecin (SN-38), by human liver carboxylesterase. Biochem Pharmacol 52: 1103-1111.

11) Atsumi R, Suzuki W, Hakusui H. (1991) Identification of the metabolites of irinotecan, a new derivative of camptothecin, in rat bile and its biliary excretion. Xenobiotica. 21(9):1159-69.

12) Ando Y, Saka H, Ando M, Sawa T, Muro K, Ueoka H, Yokoyama A, Saitoh S, Shimokata K, Hasegawa Y. (2000) Polymorphisms of UDP-glucuronosyltransferase gene and irinotecan toxicity: a pharmacogenetic analysis. Cancer Res. 60(24):6921-6.

13) Deeken JF, Slack R, Marshall JL. (2008) Irinotecan and uridine diphosphate glucuronosyltransferase $1 \mathrm{~A} 1$ pharmacogenetics: to test or not to test, that is the question. Cancer. 113(7):1502-10.
14) Takeda Y, Kobayashi K, Akiyama Y, Soma T, Handa S, Kudoh S, Kudo K. (2001) Prevention of irinotecan (CPT-11)-induced diarrhea by oral alkalization combined with control of defecation in cancer patients. Int J Cancer 92: 269-275.

15) Treinen-Moslen M, Kanz MF. (2006) Intestinal tract injury by drugs: Importance of metabolite delivery by yellow bile road. Pharmacol Ther. 112(3):649-67. Review.

16) Chu XY, Kato Y, Sugiyama Y. (1997) Multiplicity of biliary excretion mechanisms for irinotecan, CPT-11, and its metabolites in rats. Cancer Res 57: 1934-1938.

17) Lokiec F, Canal P, Gay C, Chatelut E, Armand JP, Roche H, Bugat R, Goncalves E, Mathieu-Boue A. (1995) Pharmacokinetics of irinotecan and its metabolites in human blood, bile, and urine. Cancer Chemother Pharmacol 36: 79-82.

18) Takasuna K, Hagiwara T, Hirohashi M, Kato M, Nomura M, Nagai E, Yokoi T, Kamataki T. (1996) Involvement of beta-glucuronidase in intestinal microflora in the intestinal toxicity of the antitumor camptothecin derivative irinotecan hydrochloride (CPT-11) in rats. Cancer Res. 56(16):3752-7.

19) Masuzawa T, Fujitani K, Hirao M, Kashiwazaki M, Ikenaga M, Mishima H, Nakamori S, Tsujinaka T, Takeda M. (2008) A fatal case of small cell type undifferentiated carcinoma of the esophagus with sudden diarrhea and bloody discharge by CPT-11. Gan To Kagaku Ryoho. 35(10):1741-4. in Japanese.

20) Kobayashi K, Bouscarel B, Matsuzaki Y, Ceryak S, Kudoh S, Fromm H. (1999) pH-dependent uptake of irinotecan and its active metabolite, SN-38, by intestinal cells. Int J Cancer 83: 491-496.

21) Ando M, Kobayashi K, Yoshimura A, Kurimoto F, Seike M, Nara M, Moriyama G, Mizutani H, Hibino S, Gemma A, Okano T, Shibuya M, Kudoh S. (2004) Weekly administration of irinotecan (CPT-11) plus cisplatin for refractory or relapsed small cell lung cancer. Lung Cancer 44: 121-127.

22) Hino M, Kobayashi K, Yoshimura A, Takeda Y, Hisakatsu S, Yoneda S, Gemma A, Moriya H, Kudoh S. (2006) Weekly administration of irinotecan (CPT-11) plus cisplatin for non-small cell lung cancer. Anticancer Res. 26(6C):4697-703.

23) Takeda Y, Tsuduki E, Izumi S, Hojo M, Kamimura M, Naka G, Kobayashi K, Kudo K. (2005) A phase I/II trial of irinotecan-cisplatin combined with an anti-late-diarrhoeal programme to evaluate the safety and antitumour response of this combination therapy in patients with advanced non-small-cell lung cancer. Br J Cancer. 93(12):1341-9.

24) Valentí Moreno V, Brunet Vidal J, Manzano Alemany H, Salud Salvia A, Llobera Serentill M, Cabezas Montero I, Servitja Tormo S, Sopena Bert E, Gumà Padró J. (2006) Prevention of irinotecan associated diarrhea by intestinal alkalization. A pilot study in gastrointestinal cancer patients. Clin Transl Oncol. 8(3):208-12.

25) Hamada A, Aoki A, Terazaki H, Ito K, Yokoo K, Sasaki Y, Saito H. (2005) Pharmacokinetic changes of irinotecan by intestinal alkalinization in an advanced colorectal cancer patient. Ther Drug Monit. 27(4):536-8.

26) Tamura T, Yasutake K, Nishisaki H, Nakashima T, Horita K, Hirohata S, Ishii A, Hamano K, Aoyama N, Shirasaka D, Kamigaki T, Kasuga M. (2004) Prevention of irinotecan-induced diarrhea by oral sodium bicarbonate and influence on pharmacokinetics. Oncology. 67(5-6):327-37.

27) Ikegami T, Ha L, Arimori K, Latham P, Kobayashi K, Ceryak S, Matsuzaki Y, Bouscarel B. (2002) Intestinal alkalization as a possible preventive mechanism in irinotecan (CPT-11) -induced diarrhea. Cancer Research 62:179-187. 